Journal of Animal and Veterinary Advances 11 (4): 462-469, 2012

ISSN: $1680-5593$

(C) Medwell Journals, 2012

\title{
Association Between Enrofloxacin and N-Acetylcysteine in Recurrent Bronchopneumopathies in Dogs Caused by Biofilm Producer Bacteria
}

\author{
${ }^{1}$ Anna Rita Attili, ${ }^{1}$ Matteo Cerquetella, ${ }^{2}$ Fabrizio Pampurini, ${ }^{1}$ Fulvio Laus, \\ ${ }^{1}$ Andrea Spaterna and ${ }^{1}$ Vincenzo Cuteri \\ ${ }^{1}$ School of Medical Veterinary Sciences, University of Camerino, \\ Via Circonvallazione 93/95, 62024 Matelica, Italy \\ ${ }^{2}$ Bayer Animal Healthcare, Viale Certosa 130, 20156 Milan, Italy
}

\begin{abstract}
To evaluate the efficacy of enrofloxacin and $\mathrm{N}$-acetylcysteine combination in the treatment of recurrent bronchopneumopathies caused by biofilm producer bacteria, a total of 30 dogs with recurrent respiratory diseases were examined. Bronchoalveolar lavage fluid of each animal was submitted to bacteriological and cytological examinations. Twelve patients have been treated with the above mentioned combination orally or by using an aerosol. Three dogs were randomly selected to be orally treated with Enrofloxacin only and another group of three animals has been randomly chosen to test the treatment with $\mathrm{N}$-acetylcysteine only. Moreover, the in vitro sensitivity towards a panel of antibiotics for both biofilm and not biofilm producing bacteria was evaluated and correlation between bacterial sensitivity and biofilm production was evaluated. One animal was bacteriologically negative while biofilm producer bacteria have been identified in $19(65.5 \%)$ out of the 29 bacteriological positive dogs. Biofilm formation and its abundance decreased bacterial sensitivity towards enrofloxacin $(\mathrm{p}<0.01)$ and cephalosporin $(\mathrm{p}=0.031)$ while significant differences were not observed for the other classes of antibiotics. The association showed to be safe and effective in eliminating biofilm producer bacteria from all treated animals.
\end{abstract}

Key words: Chronic bronchopneumopathy, dog, biofilms, therapy, enrofloxacin, N-acetylcysteine

\section{INTRODUCTION}

Chronic bronchitis in dogs is a disease usually characterized by mucus overproduction and cough standing for $>2$ months (Johnson, 2005). This disease is very difficult to be treated because in these cases the inflammatory/infective agents' persist in the pulmonary tissues and there is also the heavy possibility of mucosal metaplastic changes. The infiltration with mucosal inflammatory cells and the mucosal glandular hyperplasia/hypertrophy sometimes results in irreversible bronchiectasia. This phenomenon accompanied with mucus stasis can lead to recurrent bronchopneumopathies (King, 2004).

Multiple aetiology or an acute episode of coughing may start the inflammation. The combination of viral and bacterial infection is particularly common. Bordetella bronchiseptica and other microorganisms like gramnegative enteric bacteria and Mycoplasma sp. may also play a primary or secondary role (Radhakrishnan et al., 2007). Other frequent causes are hypersensitivity disorders, fungal and parasitological infections or chronic inhalation of airway irritants. Traditionally, bacteria have been regarded as individual organisms are studied as homogeneous planktonic populations. However, in natural environments bacteria are usually found as a community of sessile organisms organized in biofilms defined as a structured community of bacterial cells enclosed in a self-produced polymeric matrix, adherent to an inert or living surface and able to exhibit an altered phenotype (Costerton et al., 1999; Donlan and Costerton, 2002). Biofilms are known both in human and in veterinary medicine and represent a real problem because of their ability to become recalcitrant to antimicrobials and to evade host's response mechanisms. Because biofilms act as a physical barrier to the penetration of antimicrobials, treatment with traditional concentrations could be ineffective (Clutterbuck et al., 2007).

Furthermore the Exopolymeric Substance matrix (EPS) that behaves as an ion exchanger and the hypobiosis that characterizes cells within a biofilms are able to sequester hydrophobic and positively charged antibiotics resulting in increased resistance to antibacterials (Costerton et al., 1999; Drenkard, 2003).

Corresponding Author: Vincenzo Cuteri, School of Medical Veterinary Sciences, Via Circonvallazione 93/95, 62024 Matelica, Italy 
Although, less is known about biofilms in animals, biofilm producer bacteria could be involved in many diseases such as pneumopathies, liver abscesses, enteritis, wound infections and mastitis (Melchior et al., 2006). Understanding the mechanical properties of biofilms especially the force required to disrupt and remove them from the tissues, it is very important for the success of antimicrobial strategies.

Recent studies showed that the mucolytic molecules such as N-Acetylcysteine (NAC), associated with an antibiotic therapy can represent an effective treatment for acute bacterial infection (Varricchio et al., 2008). NAC is a mucolytic agent used in respiratory tract diseases, able to destroy disulphide bonds in mucus and to reduce the viscosity of secretions also showing antibacterial properties (Gerrits et al., 2003). The presence of Biofilm Producer (BP) bacteria could justify the resistance to antimicrobial therapies instituted in some cases of chronic bronchopneumopathies even if the antibiotic had shown in vitro efficacy. The aim of the study was to evaluate whether recurring bronchopneumopathies associated with the presence of BP bacteria can be successfully treated with an association of an antimicrobial (enrofloxacin) and a mucolytic ( $\mathrm{N}$-acetylcysteine) even if an in vitro resistance to enrofloxacin was observed.

\section{MATERIALS AND METHODS}

Animals: Thirty $\operatorname{dog} s$, presented at the Veterinary Hospital, University of Camerino (between January, 2008 and February, 2009) and showing a variable degree of chronic dyspnoea associated with cough were included. All animals had already been treated with standard therapeutic protocols based on antibiotics with no or little improvement of symptoms.

Clinical, laboratory and instrumental evaluations: All patients underwent a physical examination, a complete hematochemical evaluation (Haematology analyser, Cell-Dyn 3500, Abbott, USA and Automatic analyser BT 3000 plus ${ }^{\circledR}$, Biotecnica Instruments, Italy) and urinalysis (Multistix ${ }^{\circledR}$, Bayer, UK-Urine specific gravity with portable refractometer, Optech, Germany-Urine sediment examination and urinary protein to creatinine ratio with Automatic analyser BT 3000 plus ${ }^{\circledR}$, Biotecnica Instruments, Italy) as well as the execution of thoracic radiographs and bronchoscopy. Two different flexible endoscopes, a fiberscope (VFS-2A, VetVu ${ }^{\circledR}, \mathrm{USA}-5,5 \mathrm{~mm}$ external diameter and $100 \mathrm{~cm}$ length) and an innovative videoendoscope (Mercury Endoscopia Italiana, Italy-4,
$2 \mathrm{~mm}$ external diameter and $90 \mathrm{~cm}$ length) were used. The reason of using two different endoscopes was that the videoendoscope was unavailable at the beginning of the study. In almost all cases, injectable general anaesthesia was performed for bronchoscopy, premedication with medetomidine (Domitor ${ }^{\circledR}$, Pfizer, Italy) at a dosage of $20 \mu \mathrm{g} \mathrm{kg}^{-1}$ and tramadol (Tramadolo ${ }^{\mathbb{1}}$, Dorom, Italy) at a dosage of 2-4 $\mathrm{mg} \mathrm{kg}^{-1}$ induction and maintenance with propofol (Propofol ${ }^{\circledR}$, Braun, Germany) at a dosage of $4-8 \mathrm{mg} \mathrm{kg}^{-1}$. One dog presenting severe dyspnoea and abundant crackles and wheezes diffused in all lung lobes has been intubated. In this case inhalatory anaesthesia was used (maintenance with a mixture isoflurane/airIsoflurane-Vet ${ }^{\circledR}$, Merial, Italy) in order to guarantee the appropriate oxygen flow during the examination. A multiparameter monitor (Poet plus 8100 , Criticare systems ${ }^{\text {(B) }}$ Inc., USA) for the anaesthetic monitoring was used. Patients were positioned in sternal recumbency with the ventral neck elevated and keeping the mouth opened with a mouth clamp. The insertion tube of the endoscope was inserted inside the trachea and a complete visualisation of the tracheobronchial tree was performed in all the subjects. When the clinical and instrumental appearance were similar in all thoracic fields, the examination followed the subsequent order: right cranial lobe, right middle lobe, accessory lobe, right caudal lobe, left cranial lobe and left caudal lobe. If there was any suspected focal lesion clinically radiographically it was first visualised.

Samplings: After having anchored the tip of the endoscope in the designed segmental or subsegmental bronchi a Bronchoalveolar Lavage (BAL) using a sterile catheter passed through endoscope suction channel was performed (McKiernan, 2005). The execution site of the lavage was chosen based on the presence of large quantity of mucus inside the bronchi. If diffuse abundance of mucus was experienced, lavage was executed in the right middle lobe. For the execution of $\mathrm{BAL}$ a lavage syringe preloaded with sterile isotonic saline stored at room temperature was used. The quantity of the fluid depended on animal's bodyweight $\left(2 \mathrm{~mL} \mathrm{~kg}^{-1}\right)$ (Padrid and McKiernan, 1999) and ranging from a minimum of $10 \mathrm{~mL}$ to a maximum of $25 \mathrm{~mL}$ (King, 2004). After liquid instillation a gentle coupage was also performed in order to obtain more valuable samples. The liquid was then immediately suctioned with the same syringe, stored in sterile tubes and successively used for bacteriological and cytological examination. The lavage was executed twice at each site. At the end of each endoscopy before the subsequent one, the endoscope 
has been cleaned with heparin charged isotonic saline, hydrogen peroxide and finally with sterile deionised water. Samples obtained divided into two aliquots and processed within $30 \mathrm{~min}$.

Cytology: One aliquot of the obtained BAL was spinned (Rotofix 32, Hettich, GMI Inc., USA) and slides obtained from the resulting cytocentrifugation were stained with MGG quick stain (Bio-Optica, Italy).

\section{Bacteriology}

Bacteriological examination: Each BAL sample was submitted to bacteriological examination. An aliquot of $200 \mu \mathrm{L}$ was cultured under aerobic and anaerobic conditions at $37^{\circ} \mathrm{C}$ for $24 \mathrm{~h}$ on Columbia Blood Agar with and without Streptococcus Selective Supplement, MacConkey Agar and Baird-Parker Agar (Oxoid, Milan, Italy). The threshold determined to define clinically relevant bacterial growth was $>1.7 \times 10^{3}$ Colony-Forming Units (CFU) $\mathrm{mL}^{-1}$ of BAL fluid (Agusti and Soler, 1997; Peeters et al., 2000).

Standard microbiological techniques and biochemical

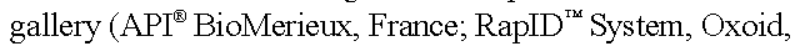
Italy) were used to identify the isolated bacteria. All specimens were also assessed for Mycoplasma organisms; $100 \mu \mathrm{L}$ of $\mathrm{BAL}$ were inoculated into Mycoplasma Broth with Mycoplasma Selective Supplement-G (Oxoid, Milan, Italy) and incubated at $4^{\circ} \mathrm{C}$ for $24 \mathrm{~h}$. After centrifugation at $2000 \mathrm{~g}$ for $20 \mathrm{~min}$, the supernatant was added to mycoplasma broth with $20 \%$ of equine serum and incubated at $37^{\circ} \mathrm{C}$ for $72 \mathrm{~h}$ in a $10 \% \mathrm{CO}_{2}$ atmosphere. Then, supernatant was transferred into Mycoplasma Agar (Oxoid, Milan, Italy) containing Mycoplasma Selective Supplement-G. Finally, the plates were incubated for 20 days at $37^{\circ} \mathrm{C}$ in a humid chamber with $10 \% \mathrm{CO}_{2}$ and examined under stereomicroscope daily after 1 week.

Antibiotic susceptibility test: For each strain an in vitro antimicrobial sensitivity test was carried out by the Disk Diffusion Method using Mueller Hinton medium (Oxoid, Milan, Italy). In case of fastidious organisms a Triptycase Soy Agar supplemented with 5\% sheep's blood (Oxoid, Milan, Italy) was used. The followed antibiotics was tested: Enrofloxacin $(5 \mu \mathrm{g})$, Amoxicillin plus Clavulanic acid $(20+10 \mu \mathrm{g})$, Cefquinome $(10 \mu \mathrm{g})$, Ceftiofur $(30 \mu \mathrm{g})$, Ceftriaxone $(30 \mu \mathrm{g})$, Doxycycline $(30 \mu \mathrm{g})$, Gentamicina $(30 \mu \mathrm{g})$, Trimethoprim plus Sulfametoxazole $(1.25+23.75 \mu \mathrm{g})$.

Sensitivity was evaluated in accordance with the CLSI breakpoints (CLSI, 2008, 2009) or with the manufacturer suggestions. The isolated bacteria were classified as Multi-Resistant (MR) or All-Resistant (AR) if a resistance to at least 5 or to all antibiotics was observed, respectively. Bacteria sensitive to 5 or more antibiotics were included in a group named $\mathrm{S}$ (sensitive).

Media for biofilm assay: Strains were inoculated in nutrient broth with $1 \%$ of glucose (Oxoid, Italy) and incubated at $37^{\circ} \mathrm{C}$ under aerobic conditions to obtain a bacterial suspension density of $0.5-\mathrm{McF}$ arland Standard inoculum (BioMerieux, France), equivalent at 0.125 absorbance value measured at $550 \mathrm{~nm}$ by spectrophotometer (Jenway Genova, England) (Washington et al., 1972).

Microtiter-plate test: The biofilms were evaluated with a spectrophotometer using the method suggested by Stepanovic et al. (2000) with some modifications. Briefly, 16 wells of a sterile 96 well flat-bottomed tissue culture plate $\left(\right.$ Serowel ${ }^{\circledR}$ Bibby Sterilin Ltd., UK) were filled with $200 \mu \mathrm{L}$ of $1: 20$ diluted bacterial suspension. Blank wells contained nutrient broth with $1 \%$ of glucose only. Staphylococcus aureus ATCC 29213, Staphylococcus epidermidis ATCC 35984, Pseudomonas aeruginosa ATCC 27853 and Streptococcus pneumoniae ATCC 6303 were used as positive controls. Two strains of Staphylococcus aureus, one strain of Staphylococcus epidermidis and one strain of Streptococcus canis previously isolated and evaluated for biofilm production were used as negative controls. Biofilms were obtained after incubation at $37^{\circ} \mathrm{C}$ for $36 \mathrm{~h}$. The content of each well was aspirated and washed three times with $250 \mu \mathrm{L}$ of sterile saline solution at pH 7.3 (Oxoid Ltd., England) to remove the planktonic organisms.

The remaining attached bacteria were fixed with $200 \mu \mathrm{L}$ of Bouin liquid (Reactifs RAL, France) per well and after 15 min the plates were emptied, washed and left to dry.

Plates were stained for 15 min with $200 \mu \mathrm{L}$ of $0.1 \%$ pure gentian violet (Carlo Erba, Milan, Italy) per well. A concentration of $0.01 \%$ pure gentian violet was used for both the reference strain and clinical isolates of Staphylococcus epidermidis. Excess stain was rinsed off three times. The bound dye was extracted using 80\% ethanol/20\% acetone (Carlo Erba, Milan, Italy) and the absorbance using a micro-ELISA plate reader (Multyscan Ascent Labsystem, Finland) at $540 \mathrm{~nm}$ wavelength was measured. The cut-off optical density value of 0.404 as three Standard Deviations (SD) above the mean Optical Density (OD) of thirty negative strains previously tested was defined.

Therapeutic trial: Those subjects whose Bronchoalveolar Lavage Fluids (BALFs) were positive for $\mathrm{BP}$ bacteria were randomly divided into two groups and 
treated differently. Animals of the first group (7 dogs) were treated orally with enrofloxacin (Baytril ${ }^{\circledR}$ flavour, Bayer, Germany) $5 \mathrm{mg} \mathrm{kg}^{-1}$ once daily, plus Nacetylcysteine (Fluimuci $^{\circledR}$ effervescent tablets, Zambon, Italy) $5 \mathrm{mg} \mathrm{kg}^{-1}$ twice daily for 14 days while those of the second one $(5$ dogs $)$ were treated with enrofloxacin (Baytril $^{\circledR}$ injectable solution 5\%, Bayer, USA) $5 \mathrm{mg} \mathrm{kg}^{-1}$ once daily, plus $\mathrm{N}$-acetylcysteine (Fluimucil $^{\circledR}$ nebulizable solution, Zambon, Italy) $500 \mathrm{mg} / \mathrm{subject}$ twice daily, for 14 days by using aerosol (Nebulflaem ${ }^{\circledR}$ F2000, Flaem, Italy). Six BP bacteria positive dogs were randomly chosen and used as control; three of them were treated orally with enrofloxacin (Baytril ${ }^{\circledR}$ flavour, Bayer, Germany) $5 \mathrm{mg} \mathrm{kg}^{-1}$ once daily for 14 days while the remaining three patients were treated with $\mathrm{N}$-acetylcysteine (Fluimucil $^{\circledR}$ effervescent tablets, Zambon, Italy) $5 \mathrm{mg} \mathrm{kg}^{-1}$ twice daily, for 14 days.

At the end of the treatment all animals underwent a physical examination, a complete hematochemical evaluation, urinalysis and a bronchoscopy with the related samplings (bacterial culture and cytology) each $\mathrm{BAL}$ was done in the same lung lobe where previous sampling was performed.

Statistical analysis: Statistical differences among the biofilms and antibiotic sensitivity test results obtained by biofilm and not biofilm producer strains were evaluated by the Fisher's exact test any significant difference between the OD values were evaluated by Student's t-test. Proportions were compared by calculating 95\% confidence intervals. The p-values below 0.05 were considered significant. The Microtiter-plate test was performed using sixteen wells for each isolate and the mean \pm standard deviation was considered. To perform analyses STATA 5.0 statistical software was used.

\section{RESULTS}

Clinical evaluation: The thirty dogs included in the study presented dyspnoea of variable degree and cough with expectoration or not. In most of the cases auscultation revealed bronchovesicular sounds, crackles and wheezes whose entity was variable depending on the severity of the disease. Cytological evaluations of blood smears showed only a mild neutrophilic leukocytosis in some cases while radiographs frequently pointed out generalized bronchial wall thickening and variably increased interstitial density. The endoscopic gross appearance was characterized by different degree of mucosal oedema and inflammation in all patients. The presence of mucus was often diffused to the whole tracheobronchial tree (Fig. 1a and c). Nineteen out of 30 subjects submitted to endoscopy revealed the presence

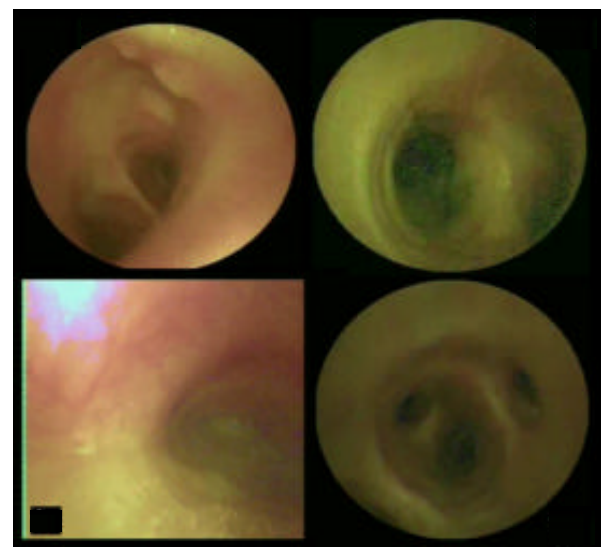

Fig. 1: a) Dog 3 before treatment: moderate oedema of the mucosa and poor presence of mucus; b) Dog 3 after treatment: improved mucosal gross appearance and absence of mucus; c) Dog 11 before treatment: severe oedema of the mucosa and heavy presence of mucus; d) Dog 11 after treatment: improved mucosal gross appearance and absence of mucus

of BP bacteria in their BALFs while the other 11 were negative or not presenting $\mathrm{BP}$ bacteria (isolates are shown in Table 1) and for this reason were excluded from the study. One of the $19 \mathrm{BP}$ bacteria positive subjects, presenting a severe dyspnoea, died few days after the first visit because of the severity of his general condition and was also excluded from the study. Results of cytological evaluation performed on BALFs showed the presence of neutrophilic inflammation with intracellular bacteria in some cases.

After the treatment each animal included in the two groups improved clinically, sometimes with complete resolution of the symptoms. Those patients who did not recover presented a decreased cough and diminished respiratory crackles and wheezes. During the treatment only one patient presented increased productive cough and increased diffuse wheezes. Hematochemical evaluation and urinalysis performed after the treatment did not pointed out any relevant difference with the previous results showing a normalisation of leukogram in almost all the animals.

Bronchoscopy revealed an improvement of the mucosal gross appearance with reduction/disappearance of inflammation/oedema and mucus in all of the patients (Fig. 1b and d). The cytological examination showed the absence of bacteria and a reduction/disappearance of neutrophils. The three control dogs treated orally with enrofloxacin (single therapy) and the three subjects treated with NAC only did not show any clinical improvement at the end of the therapy. 
Table 1: Bacteria isolated from BALFs

\begin{tabular}{|c|c|c|c|c|c|}
\hline Patient & Breed & Bacteria isolated & Biofilm production & Sensitivity to enrofloxacin & Part study \\
\hline 1 & Mixed & Acinetobacter calcoaceticus & Pos & Resistant & Yes \\
\hline 2 & Lab ret & Stophylococcus epidermidis & Pos & Sensible & Yes \\
\hline 3 & Boxer & Alcaligenes faecalis & Pos & Resistant & Yes \\
\hline 4 & Mixed & Streptococcus pne umoniae & Pos & Resistant & Deceased \\
\hline 5 & Mixed & Stophylococcus lugdunensis & Pos & Resistant & Yes \\
\hline 6 & Mixed & Corynebacterium jeikeium & Pos & Resistant & Yes \\
\hline 7 & Mixed & Pseudomonas aeruginosa & Pos & Resistant & Yes C.G. \\
\hline 8 & Boxer & Streptococcus mitis & Pos & Resistant & Yes \\
\hline 9 & Epa bret & Cellulomonas $A 3 / A 4$ & Pos & Resistant & Yes \\
\hline 10 & Engl set & Stophylococcus lugdunensis & Pos & Resistant & Yes C.G. \\
\hline 11 & Mixed & Streptococcus pne umoniae & Pos & Resistant & Yes \\
\hline 12 & Engl set & Corynebacterium $\mathrm{CDC}$ group $\mathrm{G}(\mathrm{G} / \mathrm{LD})$ & Pos & Resistant & Yes \\
\hline 13 & Mixed & Stophylococcus intermedius & Pos & Resistant & Yes \\
\hline 14 & Pointer & Streptococcus canis & Pos & Resistant & Yes \\
\hline 15 & Mixed & Corynebacterium jeikeium & Pos & Resistant & Yes C.G. \\
\hline 16 & Mixed & Pseudomonas aeruginosa & Pos & Resistant & Yes \\
\hline 17 & Poodle & Stophylococcus sciuri & Pos & Resistant & Yes NAC \\
\hline 18 & Mixed & Escherichia coli & Pos & Resistant & Yes NAC \\
\hline 19 & Pointer & Stophylococcus aureus & Pos & Resistant & Yes NAC \\
\hline 20 & Mixed & Stophylococcus sciuri & Neg & Sensible & Excluded \\
\hline 21 & Mixed & - & Neg & - & Excluded \\
\hline 22 & Mixed & Micrococcus sp. & Neg & Sensible & Excluded \\
\hline 23 & Mixed & Micrococcus sp. & Neg & Sensible & Excluded \\
\hline 24 & Lab Ret & Stophylococcus xylosus & Neg & Resistant & Excluded \\
\hline 25 & Spitz & Pseudomonas aeruginosa & $\mathrm{Neg}$ & Resistant & Excluded \\
\hline 26 & Bldhound & Stophylococcus epidermidis & Neg & Sensible & Excluded \\
\hline 27 & Eng Set & Micrococcus sp. & $\mathrm{Neg}$ & Sensible & Excluded \\
\hline 28 & Mixed & Stophylococcus xylosus & Neg & Sensible & Excluded \\
\hline 29 & Mixed & Escherichiacoli & $\mathrm{Neg}$ & Sensible & Excluded \\
\hline 30 & Mixed & Gemella haemolysans & Neg & Sensible & Excluded \\
\hline
\end{tabular}

Part Participation to the study; Lab Ret $=$ Labrador Retriever; Epa Bret $=$ Epagneul Breton; Set $=$ English Setter; Bldhound $=$ Bloodhound; Pos $=$ Positive; $\mathrm{Neg}=$ Negative; $\mathrm{C} . \mathrm{G} .=$ Control group; $\mathrm{NAC}=\mathrm{N}-$ Acetylcysteine group

Table 2: Antibiotic sensitivity of bacteria isolated from BALFs

\begin{tabular}{lllll} 
Bacteria & \multicolumn{1}{c}{ ER } & \multicolumn{1}{c}{ MR } & \multicolumn{1}{c}{ AR } & \multicolumn{1}{c}{$\mathrm{S}$} \\
\hline BP $[\mathrm{n}=19]$ & $100 \% \%^{\mathrm{a}}$ & $26.3 \% \%^{\mathrm{b}}$ & $63.2 \%^{\mathrm{c}}$ & $10.5 \%^{\mathrm{d}}$ \\
& & $(4.5-48.1)$ & $(39.3-87.0)$ & $(-4.7-25.7)$ \\
$\mathrm{NBP}[\mathrm{n}=10]$ & \multirow{2}{*}{$20.0 \%^{\mathrm{a}}$} & $50.0 \% \%^{\mathrm{b}}$ & $30.0 \% \%^{\mathrm{c}}$ & $20.0 \% \%^{\mathrm{d}}$ \\
& & $(12.3-87.7)$ & $(-4.5-64.5)$ & $(-10.2-50.2)$ \\
\hline
\end{tabular}

BP: Biofilm Producer; NBP: Not Biofilm Producer; ER: Enrofloxacin Resistant; MR: Multi Resistant ( $\geq 5$ antibiotics); AR: All Resistant; S: Sensitive ( $\geq 5$ antibiotics); (.): Confidence; Interval $95 \% ;\left({ }^{2} \chi=20.99\right.$, $\mathrm{p}<10^{-4} ;{ }^{b} \chi=1.63, \mathrm{p}=0.202 ;{ }^{\mathrm{c}} \chi=2.88, \mathrm{p}=0.089 ;{ }^{\mathrm{d}} \chi=0.49, \mathrm{p}=0.482$ )

Microbiological evaluation: Microbiological cultures from bronchial samples were positive in twenty nine out of thirty dogs (97\%). Nineteen $(65.5 \%)$ showed an infection with BP bacteria while in ten cases $(34.5 \%)$ Not Biofilm Producer (NBP) strains were isolated. The bacteria isolated are shown in Table 1. All positive BALFs recorded a bacterial concentration $>2.0 \times 10^{3}$ colonyforming units per millilitre. Mycoplasma organisms were not detected from any of the dogs examined.

The antibiotic sensitivity was performed for each strain and the in vitro activity of enrofloxacin and other antibiotics were compared between the two groups of bacteria (Table 2).

After treatment BALF samples were all bacteriologically negative. The dogs owing to the two control groups treated with enrofloxacin or NAC continued to show a positive bacterial culture. The sensitivity data revealed the presence of many MR and AR organisms both in biofilm producer and not biofilm producer population. No significant evidences $(\mathrm{p}>0.48)$ were recorded between $\mathrm{BP}(89.5 \%, \mathrm{n}=19)$ and NBP strains $(80 \%, \mathrm{n}=10)$ in relation to antibiotic resistance to $>5$ antibiotics, except to enrofloxacin where a significant difference $(\mathrm{p}<0.01)$ was recorded (Table 2$)$. All BP strains showed resistance to enrofloxacin and proved to be also resistant to at least 4 antibiotics tested; resistance to sulphonamides and tetracyclines appeared to be more evident.

Only one BP bacterium (5.26\%; $\left.\mathrm{CI}_{95}-4.1-58.4\right)$, Alcaligenes faecalis showed a sensitivity to cephalosporins, $\beta$-lactam agents and tetracyclines. Analysing biofilm formation, different levels of ODs were observed. The OD mean observed for BP and NBP strains was $1.543 \pm \mathrm{SD} 0.858(\mathrm{n}=19)$ and $0.227 \pm \mathrm{SD} 0.076(\mathrm{n}=10)$, respectively.

Table 3 shows the OD levels recorded for the resistant strains both to enrofloxacin and other antibiotics. Among bacteria resistant to 5 or more antibiotics, 18 out of 26 were BP microorganisms while 8 strains were NBP and showed a sensitivity to enrofloxacin only $2 \mathrm{BP}$ strains out of 3 were sensitive to 5 or more chemobiotics. Considerable difference was observed in the abundance of biofilms produced by enrofloxacin $(\mathrm{p}=0.0008)$ and by cephalosporins $(\mathrm{p}=0.031)$ resistant and sensitive strains while no differences were recorded for amoxicillin/CA and doxycycline. 
Table 3: Mean absorbance values (OD at $450 \mathrm{~nm}$ ) in resistant and sensitive bacteria towards tested antibiotics

\begin{tabular}{llllll}
\hline AS & $\geq 5$ antibiotics & Enrofloxacin & Cephalosporins & Amoxicillin/CA & Tetracyclines \\
\hline RB & $1.177^{\mathrm{a}}(0.794-1.561)$ & $1.423^{\mathrm{b}}(1.015-1.832)$ & $1.337^{\mathrm{c}}(0.878-1.796)$ & $1.056^{\mathrm{d}}(0.670-1.443)$ & $1.1500^{\circ}(0.759-1.542)$ \\
Number & $\mathrm{n}=26$ & $\mathrm{n}=21$ & $\mathrm{n}=20$ & $\mathrm{n}=20$ & $\mathrm{n}=26$ \\
SB & $0.324^{\mathrm{a}}(-0.391-1.039)$ & $0.211^{\mathrm{b}}(0.148-0.275)$ & $0.538^{\mathrm{c}}(0.114-0.963)$ & $1.162^{\mathrm{d}}(0.236-2.088)$ & $0.558^{\circ}(-0.294-1.411)$ \\
Number & $\mathrm{n}=3$ & $\mathrm{n}=8$ & $\mathrm{n}=9$ & $\mathrm{n}=9$ & $\mathrm{n}=3$ \\
\hline
\end{tabular}

AS: Antibiotic Susceptibility; RB: Resistant Bacteria; SB: Sensitive Bacteria to $\geq 5$ antibiotics; CA: Clavulanic Acid; $\left({ }^{a} p=0.139 ;{ }^{b} p=0.0008 ;{ }^{c} p=0.031\right.$; ${ }^{\mathrm{d}} \mathrm{p}=0.785 ;{ }^{\mathrm{e}} \mathrm{p}=0.310$ )

Three strains showed a sensitivity to gentamicin recording a low adsorbance mean value of $0.420\left(\mathrm{CI}_{95}{ }^{-}\right.$ $0.461-1.301)$ in comparison to a high OD mean value of $1.166\left(\mathrm{CI}_{95} 0.780-1.553 ; \mathrm{t}=-1.322, \mathrm{p}=0.200\right)$ observed for the other 26 resistant bacteria. No relation was found between biofilm production and resistance in the case of sulphonamides $(\mathrm{t}=-0.902, \mathrm{p}=0.375)$.

\section{DISCUSSION}

In the last decades, one of the most convincing hypotheses to explain therapy resistance is the ability of many microorganisms to growth in biofilms in infected tissues thus, developing an innate resistance to almost all antibiotics.

Since, 1990 s biofilms were investigated in relation to chronic infections and biofilm related-infections by Grampositive (Staphylococcus epidermidis and $S$. aureus) and Gram-negative bacteria in human medicine (Donlan and Costerton, 2002).

Various organisms of veterinary importance have been successfully grown as biofilms including Corynebacterium pseudotuberculosis, Escherichia coli, Pseudomonas aeruginosa, S. aureus, Staphylococcus hyicus, Acinetobacter baumanii, Actinobacillus equuli and Aeromonas hydrophila (Costerton et al., 1999; Vaneechoutte et al., 2000, Lynch et al., 2002).

Some of these bacteria isolated from gastroenteritis, wound infections, septicaemia, pneumonia and abortion in humans, horses, cattle and pigs are reported to be resistant to some penicillins (Clutterbuck et al., 2007).

A limited number of studies were carried out in veterinary medicine to investigate the role of biofilm producer Streptococcus pneumoniae in the stages of bronchial colonization (Clutterbuck et al., 2007). Many of these bacterial species are also major pathogens involved in airway infections and difficulties in treating recurrent infections might be related to the ability of pathogens to form biofilms (Van der Linden et al., 2009).

By this study, it was possible to report the in vitro growth of new biofilm microorganisms involved in recurrent bronchopneumopathies in dog not pointed out in literature yet. It is known that bacteria in biofilms have a slow growth and can become 10-1000 times more resistant to the effects of antimicrobial agents as compared to planktonic growing bacteria of the same strains (Costerton et al., 1999; Mah and O'Toole, 2001).

The in vitro results obtained in this research showed that multi and all resistance were observed in the two populations of microorganisms. In previous studies, it was proved that the biofilm formation could increase the antibiotic resistance and that the decreased antibiotic diffusion through the extensive biofilm matrix and the reduced metabolic activity of bacteria within biofilms may affect the antibiotic activity (Domingue et al., 1994). In this study, no relation was observed between biofilm production and antibiotic resistance, except for enrofloxacin, towards which all BP strains (100\%) appeared to be resistant. Moreover, it was observed that biofilms did not significantly influence the sensitivity towards sulphonamides, $\beta$-lactam agents and tetracyclines, nevertheless higher mature biofilm volumes were recorded in resistant bacteria for each class of antibacterial agents (Table 3). Interestingly, in the case of amoxicillin and clavulanic acid the sensitive strains to the combination seemed to produce more biofilms (OD 1.162; $\mathrm{n}=9$ ), than the resistant ones (OD 1.056; $\mathrm{n}=20$ ). What observed for amoxicillin and clavulanic acid sensitive strains was due at the occurrence that the same strains resulted to be resistant to enrofloxacin too. Because at the base of antibiotic resistance there are refined mechanisms that the bacteria put on act to increase their survival (Stewart and Costerton, 2001), it is reasonable to assert that plasmid acquired resistance could be occur for the panel of antibiotics tested except for enrofloxacin, confirming the hypothesis of rarely trend of fluoroquinolone to acquire resistance by plasmids while probably it was a biofilms reduced susceptibility. Present data showed an in vitro resistance of enrofloxacin while $\mathrm{BP}$ bacteria resulted in vivo sensible when the fluoroquinolone in association with NAC was used. The negative bacteriological culture and symptoms remission without relapses, confirmed the important activity of mucolytic molecule. The results reported in the present research support the implementation of clinical studies aimed at demonstrating the real advantages of fluoroquinolones in association with $\mathrm{NAC}$ in the in vivo therapy of recurrent bronchopneumopathies. The 
treatment used showed an efficacy of $100 \%$ for what concern bacteria elimination from animals' lower airways as it is testified by the absence of such agents in bacterial cultures and cytological samples obtained from control bronchoscopies in both groups. Almost all animals showed also an improvement 16 and sometimes a clinical resolution; the fact that not all the patients have clinically resolved and one presented even a worsening in cough and wheezes is probably due to the chronicity of the disease accompanied with the likely subsequent mucosal metaplastic changes that could happens in such cases.

No patient showed any pathological change in laboratory tests results performed after the treatment if compared with those executed previously with also a reduction in the neutrophilic leukocytosis pointed out in some cases with the former exams. With regard to the administering way of the two drugs it is important to point out that aerosol therapy, even if as efficacious as the oral one, demonstrated to be more difficult to carry out because of the large volume of fluid to nebulize together with the difficulties inherent the aerosol therapy itself. The large volume of fluid had also negative effects on the length of each treatment. It should also be pointed out that at the end of the therapy the two molecules' rests were usually partially precipitated inside the administering ampulla even if this did not affected the positive outcome of the treatment.

\section{CONCLUSION}

This study shows that it is possible to infer that even if in the present research only twelve patients have been tested with the proposed therapeutic protocol, the association between enrofloxacin and N-acetylcysteine given both orally as well as nebulized can be considered efficacious and safe in the dog in improving recurrent bronchopneumopathies associated with BP bacteria even an in vitro resistance was demonstrated. Finally, the patients treated with enrofloxacin or NAC alone in which the isolated $\mathrm{BP}$ bacteria showed an in vitro resistance to enrofloxacin did not improve this represents a further confirm of the efficacy of the drugs association.

\section{ACKNOWLEDGEMENT}

The study was supported by Bayer Animal Health Care, Milan, Italy.

\section{REFERENCES}

Agusti, C. and N. Soler, 1997. Bacterial colonization of distal airways in healthy subjects and chronic lung disease: A bronchoscopic study. Eur. Respir. J., 10: 1137-1144.
CLSI, 2008. Performance Standard for Antimicrobial Disk Susceptibility Tests. Clinical and Laboratory Standards Institute, Wayne, PA., USA.

CLSI, 2009. Performance Standards for Antimicrobial Disk and Dilution Susceptibility Tests for Bacteria Isolated from Animals. 3rd Edn., Clinical and Laboratory Standards Institute, Wayne, PA., USA.

Clutterbuck, A.L., E.J. Woods, D.C. Knottenbelt, P.D. Clegg, C.A. Cochrane and S.L. Percival, 2007. Biofilms and their relevance to veterinary medicine. Vet. Microbiol., 121: 1-17.

Costerton, J.W., P.S. Stewart and E.P. Greenberg, 1999. Bacterial biofilms: A common cause of persistent infections. Science, 284: 1318-1322.

Domingue, G., B. Ellis, M. Dasgupta and J.W. Costerton, 1994. Testing antimicrobialsusceptibilities of adherent bacteria by a method that incorporates guidelines of the National Committee for Clinical Laboratory Standards. J. Clin. Microbiol., 32: 2564-2568.

Donlan, R.M. and J.W. Costerton, 2002. Biofilms: Survival mechanisms of clinically relevant microorganisms. Clin. Microbiol. Rev., 15: 167-193.

Drenkard, E., 2003. Antimicrobial resistance of Pseudomonas aeruginosa biofilms. Microb. Infect., 5: 1213-1219.

Gerrits, C.M., R.M. Herings, H.G. Leufkens and J.W. Lammers, 2003. N-acetylcysteine reducesthe risk of re-hospitalisation among patients with chronic obstructive pulmonary disease. Eur. Respir. J., 21: 795-798.

Johnson, L.R., 2005. Diseases of the Small Airways. In: Textbook of Veterinary Internal Medicine, Ettinger, S.J. and E.C. Feldman, (Eds.). Elsevier Saunders, UK., pp: 1233-1239.

King, L.G., 2004. Textbook of Respiratory Disease in Dogs and Cats. Saunders, St. Louis, Pages: 665.

Lynch, M.J., S. Swift, D.F. Kirke, C.W. Keevil, C.E. Dodd and P. Williams, 2002. The regulation ofbiofilm development by quorum sensing in Aeromonas hydrophila. Environ. Microbiol., 4: 18-28.

Mah, T.F. and G.A. O'Toole, 2001. Mechanisms of biofilm resistance to antimicrobial agents. Trends Microbiol., 9: 34-39.

McKiernan, B.C., 2005. Bronchoscopy. In: Veterinary Endoscopy for the Small Animal Practitioner, McCarthy, T.C. (Ed.). Elsevier Saunders, UK., pp: 201-227.

Melchior, M.B., J. Fink-Gremmels and W. Gaastra, 2006. Comparative assessment of the antimicrobial susceptibility of Staphylococcus aureus isolates from bovine mastitis in biofilm versus planktonic culture. J. Vet. Med., 53: 326-332. 
Padrid, P.A. and B.C. McKiernan, 1999. Tracheobronchoscopy of the Dog and Cat. In: Small Animal Endoscopy, Tams, T.R. (Ed.). 2nd Edn., Mosby, St. Louis, pp: 377-396.

Peeters, D.E., B.C. McKiernan, R.M. Weisiger, D.J. Schaeffer and C. Clercx, 2000. Quantitative bacterial cultures and cytological examination of bronchoalveolar lavage specimens in dogs. J. Vet. Internal Med., 14: 534-541.

Radhakrishnan, A., K.J. Drobatz, W.T. Culp and L.G. King, 2007. Community-acquired infectious pneumonia in puppies: 65 cases (1993-2002). J. Am. Vet. Med. Assoc., 230: 1493-1497.

Stepanovic, S., D. Vukovic, I. Dakic, B. Savic and M. Svabic-Vlahovic, 2000. A modifiedmicrotiter-plate test for quantification of Staphylococcal biofilm formation. Microb. Math., 40: 175-179.

Stewart, P.S. and J.W. Costerton, 2001. Antibiotic resistance of bacteria in biofilms. Lancet, 358: $135-138$.
Van der Linden, M., A. Al-Lahham, W. Nicklas and R.R. Reinert, 2009. Molecular characterization of pneumococcal isolates from pets and laboratory animals. PLoS ONE, Vol. 4, No. 12. 10.1371/journal.pone.0008286.

Vaneechoutte, M., L.A. Devriese, L. Dijkshoorn, B. Lamote, P. Deprez, G. Verschraegen and F. Haesebrouck, 2000. Acinetobacter baumanniiinfected vascular catheters collected from horses in an equine clinic. J. Clin. Microbiol., 38: 4280-4281.

Varricchio, A., M. Capasso, M.D. Gioacchino and G. Ciprandi, 2008. Inhaled thiamphenicol and acetilcysteine in children with acute bacterial rhinopharyngitis. Int. J. Immunopathol. Pharmacol., 21: 625-630.

Washington, J.A., E. Warren and A.G. Karlson, 1972. Stability of barium sulfate turbidity standards. Applied Microbiol., 24: 1013-1013. 